\title{
The mating system of Liatris helleri (Asteraceae), a threatened plant species
}

\author{
MARY JO W. GODT* \& J. L. HAMRICK \\ Departments of Botany and Genetics, University of Georgia, Athens, Georgia 30602, U.S.A.
}

\begin{abstract}
Multilocus outcrossing rates were estimated for seven populations of Liatris helleri, a rare insect-pollinated composite. The mean multilocus outcrossing rate was 0.97 (SE $=0.02$ ). None of the populations examined had multilocus outcrossing rates that differed significantly from 1.00, suggesting that the species is self-incompatible. Seed set was insignificant for 770 bagged floral heads, lending further support for this view. A small but significant amount of biparental inbreeding was detected in three of the seven populations.
\end{abstract}

Keywords: conservation, endangered plant, Liatris helleri, mating system, outcrossing rate, self-incompatibility.

\section{Introduction}

Appropriate management of rare plant species requires an understanding of their life-history characteristics. One of the life-history features critical to successful management is the mating system of the species (Karron, 1991). Knowledge of the mating system permits assessment of potential problems with the regeneration of natural and ex situ populations. For instance, small populations of selfincompatible plant species may not obtain sufficient pollen for maximum seed set if there is a small number of reproductive individuals or cross-compatible plants, or if there is variation in phenology among individuals (Les et al., 1991; Whisler \& Snow, 1992; Widén, 1993). In addition, self-compatible plants that typically outcross may experience higher rates of selfing and consequently higher inbreeding depression in small populations (Barrett \& Kohn, 1991). In contrast, small population size may pose no particular recruitment threat to selfing plants unless necessary pollinator service is diminished. Population size enhancement, the introduction of plants carrying a variety of incompatibility alleles, hand-pollination and pollinator introductions could be utilized to ameliorate reproductive difficulties.

Ex situ conservation plans can also be enhanced by knowledge of the mating system. For instance, there is no need to maintain barriers to pollen flow among populations of selfing plants maintained offsite. In other cases, manipulation of gene flow (e.g.

\footnotetext{
${ }^{*}$ Correspondence.
}

assisted movement of pollen among self-incompatible plants) may be desirable.

\section{The study species}

In this study we obtain quantitative estimates of the mating system of Liatris helleri (Porter) Porter, a rare herb of the south-eastern U.S. One objective was to examine whether inbreeding was correlated with population size. To this end, we collected $L$. helleri seeds from populations that ranged in size from approximately fifty flowering plants to over several hundred.

Liatris helleri (Heller's blazing star) is a rare highelevation plant endemic to a small area of the Blue Ridge Mountains of North Carolina. A sun-loving perennial, $L$. helleri is found on open rocky outcrops, ledges and cliff faces and rarely, at wood edges, at high (1100 to $1800 \mathrm{~m}$ ) elevations in generally shallow soils. The perennating organ is a corm-like rootstock that produces tufts of basal leaves. Flowering individuals send up several or more stems that reach $40 \mathrm{~cm}$ in height and are topped by a showy determinate spike of perfect, lavender to purple flowers. Seven to 10 florets form an $L$. helleri head (Massey et al., 1983). Flowering occurs from late July to September (M.J.W.G., pers. obs.), with fruit-set occurring from September to October (Radford et al., 1968). A variety of bees, butterflies, and moths visits the flowers (M.J.W.G., pers. obs.).

In $1989, L$. helleri was given 'threatened' status under the United States Endangered Species Act. Various factors make the species vulnerable to 
extinction. One is the small number (seven) of extant populations (U. S. Fish and Wildlife Service, 1989). Demographic stochasticity and extremes of natural climatic conditions (e.g. severe drought) could easily lead to a decrease in the number of populations, many of which are small. In addition, the restricted range of the species makes it vulnerable to catastrophic events. Tangible threats to the species include (1) the recreational development of private sites that harbour populations, (2) succession, and (3) trampling by visitors and hikers who enjoy the scenic views obtained from the rock surfaces on which $L$. helleri grows (U. S. Fish \& Wildlife Service, 1989).

\section{Materials and methods}

\section{Collection and treatment of samples}

Liatris helleri seeds were collected in autumn of 1992 from seven North Carolina populations. Sample sizes were restricted because of concern for the viability of populations. Populations (locations are not given because of the vulnerability of the species to collectors) were located within a $30 \mathrm{~km}$ radius. Seeds were sorted from chaff, marked by maternal family, planted shallowly in flats and stratified in a cold $\left(2-4^{\circ} \mathrm{C}\right)$ room. After 3 months the flats were moved to a greenhouse. Seedlings began emerging after about 10 days, and whole plants were used in enzyme extractions that began 5 weeks after seedling emergence. After several additional weeks, plants reached sufficient size to permit nondestructive sampling, and plants were preserved for restoration. Enzymes were extracted from leaves of seedlings by crushing leaf tissue in a mortar and pestle with the addition of an extraction buffer (Mitton et al., 1979). Extracts were absorbed onto chromatography paper wicks that were stored at $-70^{\circ} \mathrm{C}$ until needed for electrophoresis.

\section{Electrophoresis and statistical analysis}

Electrophoresis was performed using starch (Sigma) gels. Gels were stained for seven enzyme systems to resolve nine polymorphic allozyme loci: leucine aminopeptidase (Lap, EC 3.4.11.-), phosphoglucomutase (Pgm-1 and -2, EC 5.4.2.2), diaphorase (Dia-1, EC 1.8.1.4), menadione reductase (Mrr-2, EC 1.6.99.2), fluorescent esterase ( $\mathrm{Fe}$-2, EC 3.1.1.1), phosphogluco-isomerase (Pgi-2 and -3, EC 5.3.1.9), and triosese phosphate isomerase (Tpi-1, EC 5.3.1.1). The following buffer systems of Soltis et al. (1983) were used in the analyses: System 10 (for LAP and
PGM); System 7 (for DIA and MNR); and a modified System 8 (for FE, PGI and TPI). Stain recipes were from Soltis et al. (1983), except for DIA and MNR which were from Cheliak \& Pitel (1984). Subsets of the nine loci (Table 1) were used to estimate outcrossing rates in different populations, because not all loci were polymorphic in every population.

Single locus $\left(t_{\mathrm{s}}\right)$ and multilocus $\left(t_{\mathrm{m}}\right)$ outcrossing estimates, pollen allele frequencies, and maternal inbreeding coefficients ( $F$ values) were estimated by the computer program of Ritland \& Jain (1981) which is based on the mixed-mating model of Brown \& Allard (1970). Assumptions of the mixed-mating model are that each mating results either from a random mating event or a selfing event; that selection has not occurred between the time of fertilization and the time of assay; that the likelihood of an outcross event is independent of maternal genotype; and that maternal individuals obtain equivalent samples of outcross pollen (Clegg, 1980). An additional assumption of the multilocus estimation procedures is that the study loci are unlinked (Shaw et al., 1981).

Maternal genotypes were inferred from progeny arrays (by the method of Brown \& Allard (1970)), because leaves of maternal individuals were in poor condition at the time of seed harvest. For those loci that had more than three alleles in a population the lowest-frequency alleles were pooled for statistical analyses because Ritland's mating system program handles a maximum of three alleles at a locus. Standard errors for the outcrossing estimates were based on 200 bootstraps.

For population estimates of outcrossing rates, an average of 12 individuals per family was assayed. In total, 1104 individuals representing 95 families were analysed. In addition, 48 individuals were analysed

Table 1 The number of alleles found at each locus analysed for the mating system of Liatris helleri

\begin{tabular}{lccccccc}
\hline & \multicolumn{7}{c}{ Population } \\
\cline { 2 - 8 } Locus & BH & CR & GF & RR & SH & TR & YO \\
\hline Dia-1 & 2 & 2 & 2 & 2 & 2 & 2 & 2 \\
Fe-2 & 2 & 2 & 2 & 2 & 2 & 3 & 2 \\
Lap & 2 & 3 & 3 & 3 & 4 & 3 & 2 \\
Mnr-2 & 5 & 5 & 4 & 5 & 5 & 4 & 6 \\
Pgi-2 & 4 & 2 & 2 & 2 & 2 & 2 & 2 \\
Pgi-3 & 1 & 4 & 1 & 1 & 1 & 5 & 1 \\
Pgm-1 & 2 & 2 & 2 & 3 & 3 & 2 & 2 \\
Pgm-2 & 1 & 2 & 1 & 2 & 2 & 4 & 2 \\
Tpi-1 & 2 & 3 & 3 & 2 & 2 & 4 & 2 \\
\hline
\end{tabular}


for each of 11 families and 13 families in the GF and $\mathrm{TF}$ populations, respectively. To test for differences in pollen allele frequencies among families, the progeny of maternal individuals with the same genotype were examined using contingency chisquare tests. For homozygous mothers, the numbers of heterozygous vs. homozygous progeny were compared. At diallelic loci an even segregation ratio was assumed for heterozygous mothers, and pollen allele numbers were calculated by subtracting the maternal alleles donated to the progeny. The numbers of pollen alleles in each class were then compared across families. Not all loci could be tested because the distribution of genotypes for some loci did not conform to the number required for valid chi-square tests (i.e. genotype 'cells' should have expected values of 5 or more).

The expected inbreeding coefficient at equilibrium $\left(F_{\mathrm{e}}\right)$ was calculated (Fyfe \& Bailey, 1951) from the multilocus outcrossing rates by the equation $F_{\mathrm{e}}=\left(1-t_{\mathrm{m}}\right) /\left(1+t_{\mathrm{m}}\right)$. The expected equilibrium inbreeding coefficient and the observed inbreeding coefficient should be equal if the assumptions of Hardy-Weinberg are met, and if the mating system is the sole factor determining genotype frequencies.

To test the ability of plants to self, flowering stalks of 30 individuals were bagged in the greenhouse with either white paper bags (18 individuals) or bags constructed of very fine netting material (12 individuals). After flower stalks senesced, inflorescences were removed and the numbers of bagged heads and seeds were counted.

\section{Results}

Liatris helleri was found to be highly outcrossed, with a mean multilocus outcrossing estimate of $0.97 \pm 0.02$ (Table 2). The multilocus outcrossing rate did not differ significantly from unity for any population. The mean single-locus outcrossing estimate (mean $t_{\mathrm{s}}=0.87 \pm 0.03$ ) was somewhat lower than the multilocus estimate, and ranged from 0.78 to 1.00 for the different populations. Differences between multilocus and mean single-locus outcrossing rates for individual populations provide a measure of biparental inbreeding (Brown, 1989). We found significant differences between $t_{\mathrm{m}}$ and $t_{\mathrm{s}}$ for three (CR, RR and TR) of the seven populations examined (Table 2).

Significant differences were found between ovule allele frequencies and frequencies of successful pollen alleles at a number of loci in several populations (Table 3), indicating violations of the mixed-mating model assumptions. To examine the effect of these violations on outcrossing rate estimates in populations $\mathrm{BH}$ and $\mathrm{RR}$, two analyses were performed in which the loci with the greatest deviations were omitted. When $M n r-2$ was omitted from the analysis for RR, the multilocus outcrossing rate decreased from $0.951(\mathrm{SE}=0.037)$ to $0.949(\mathrm{SE}=0.050)$, while the mean single-locus estimate increased from 0.785 $(\mathrm{SE}=0.060)$ to $0.818(\mathrm{SE}=0.074)$. For population $\mathrm{BH}$, two loci (Lap and Tpi-1) violated model assumptions. When these were omitted from the analysis, the multilocus outcrossing rate decreased from $0.880(\mathrm{SE}=0.089)$ to $0.848(\mathrm{SE}=0.137)$, and the mean single-locus estimate fell from 0.844 $(\mathrm{SE}=0.094)$ to 0.833 ( $\mathrm{SE}=0.118)$. Since outcrossing estimates did not change significantly when loci that violated assumptions of the mixed-mating model were eliminated, all polymorphic loci were utilized in the estimation of outcrossing rates (Table 1).

A total of nineteen tests were conducted to examine whether pollen allele frequencies were similar across maternal individuals within populations. Eight

Table 2 Mating system estimates* and sampling parameters for seven Liatris helleri populations

\begin{tabular}{lcccccr}
\hline Population & $\begin{array}{c}\text { No. of } \\
\text { families }\end{array}$ & $\begin{array}{c}\text { Total no. of } \\
\text { progeny }\end{array}$ & $\begin{array}{c}\text { No. of loci } \\
\text { used }\end{array}$ & $t_{\mathrm{m}}(\mathrm{SE})$ & $t_{\mathrm{s}}(\mathrm{SE})$ & $t_{\mathrm{m}}-t_{\mathrm{s}}(\mathrm{SE})$ \\
\hline BH & 7 & 78 & 7 & $0.88(0.09)$ & $0.84(0.09)$ & $0.04(0.06)$ \\
CR & 17 & 200 & 9 & $0.97(0.03)$ & $0.78(0.04)$ & $0.19(0.03)$ \\
GF & 21 & 252 & 7 & $0.95(0.03)$ & $0.90(0.04)$ & $0.05(0.03)$ \\
RR & 10 & 119 & 8 & $0.95(0.04)$ & $0.79(0.06)$ & $0.16(0.04)$ \\
SH & 7 & 84 & 8 & $1.01(0.28)$ & $0.93(0.07)$ & $0.08(0.25)$ \\
TR & 21 & 252 & 9 & $0.96(0.03)$ & $0.85(0.05)$ & $0.11(0.03)$ \\
YO & 12 & 119 & 8 & $1.04(0.14)$ & $1.00(0.11)$ & $0.04(0.06)$ \\
Mean & & & & $0.97(0.02)$ & $0.87(0.03)$ & $0.10(0.02)$ \\
\hline
\end{tabular}

${ }^{*} t_{\mathrm{m}}$ is the multilocus outcrossing rate, $t_{\mathrm{s}}$ is the mean single-locus outcrossing rate and SE is the standard error. 
Table 3 Loci with significant differences between ovule and pollen allele frequencies in Liatris helleri populations

\begin{tabular}{|c|c|c|c|c|c|}
\hline \multirow[b]{2}{*}{ Population } & \multirow[b]{2}{*}{ Locus } & \multirow[b]{2}{*}{ Source } & \multicolumn{3}{|c|}{ Allele frequency } \\
\hline & & & 1 & 2 & 3 \\
\hline \multirow[t]{4}{*}{$\mathrm{BH}$} & \multirow[t]{2}{*}{ Lap } & Ovule & 0.071 & 0.929 & \\
\hline & & Pollen & 0.190 & 0.810 & \\
\hline & \multirow{2}{*}{ Tpi-1 } & Ovule & 0.857 & 0.143 & \\
\hline & & Pollen & 0.634 & 0.366 & \\
\hline \multirow[t]{10}{*}{ CR } & \multirow[t]{2}{*}{ Dia-1 } & Ovule & 0.735 & 0.265 & \\
\hline & & Pollen & 0.405 & 0.595 & \\
\hline & \multirow[t]{2}{*}{ Lap } & Ovule & 0.206 & 0.676 & 0.118 \\
\hline & & Pollen & 0.396 & 0.563 & 0.041 \\
\hline & \multirow{2}{*}{$M n r-2$} & Ovule & 0.206 & 0.500 & 0.294 \\
\hline & & Pollen & 0.252 & 0.379 & 0.369 \\
\hline & \multirow[t]{2}{*}{$P g i-2$} & Ovule & 0.471 & 0.529 & \\
\hline & & Pollen & 0.472 & 0.528 & \\
\hline & \multirow[t]{2}{*}{$P g m-1$} & Ovule & 0.441 & 0.559 & \\
\hline & & Pollen & 0.391 & 0.609 & \\
\hline \multirow{4}{*}{ GF } & \multirow[t]{2}{*}{$M n r-2$} & Ovule & 0.310 & 0.143 & 0.548 \\
\hline & & Pollen & 0.320 & 0.226 & 0.454 \\
\hline & \multirow[t]{2}{*}{ Pgi-2 } & Ovule & 0.381 & 0.619 & \\
\hline & & Pollen & 0.439 & 0.561 & \\
\hline \multirow{10}{*}{ RR } & \multirow[t]{2}{*}{$\mathrm{Fe}-2$} & Ovule & 0.250 & 0.750 & \\
\hline & & Pollen & 0.408 & 0.592 & \\
\hline & \multirow[t]{2}{*}{$M n r-2$} & Ovule & 0.400 & 0.350 & 0.250 \\
\hline & & Pollen & 0.292 & 0.288 & 0.420 \\
\hline & \multirow[t]{2}{*}{ Pgi-2 } & Ovule & 0.200 & 0.800 & \\
\hline & & Pollen & 0.351 & 0.649 & \\
\hline & \multirow[t]{2}{*}{$P g m-2$} & Ovule & 0.950 & 0.050 & \\
\hline & & Pollen & 0.934 & 0.066 & \\
\hline & \multirow[t]{2}{*}{$T p i-1$} & Ovule & 0.550 & 0.450 & \\
\hline & & Pollen & 0.568 & 0.432 & \\
\hline \multirow[t]{8}{*}{ TR } & \multirow[t]{2}{*}{$M n r-2$} & Ovule & 0.667 & 0.214 & 0.119 \\
\hline & & Pollen & 0.707 & 0.215 & 0.078 \\
\hline & \multirow[t]{2}{*}{ Pgi-3 } & Ovule & 0.381 & 0.310 & 0.310 \\
\hline & & Pollen & 0.264 & 0.450 & 0.286 \\
\hline & Pgm-1 & Ovule & 0.667 & 0.333 & \\
\hline & & Pollen & 0.643 & 0.357 & \\
\hline & Pgm-2 & Ovule & 0.000 & 0.762 & 0.238 \\
\hline & & Pollen & 0.001 & 0.773 & 0.227 \\
\hline YO & $\mathrm{Fe}-2$ & Ovule & 0.958 & 0.042 & \\
\hline & & Pollen & 0.866 & 0.134 & \\
\hline & Pgm-1 & Ovule & 0.958 & 0.042 & \\
\hline & & Pollen & 0.907 & 0.093 & \\
\hline
\end{tabular}

of these tests were significant $(P<0.05)$, indicating that the pollen that had been successful in fertilizing different plants varied significantly in allele frequency among maternal plants.

Inbreeding coefficients for maternal individuals ranged from -0.300 in $\mathrm{YO}$ to 0.225 in $\mathrm{SH}$, with an overall mean of -0.096 (Table 4). Four of the seven inbreeding coefficients differed significantly from zero, with one being positive (SH) and three negative (RR, TR and YO). The equilibrium inbreeding coefficients were low, with a mean of 0.021 .

For the 30 individuals with bagged flowers, we examined 770 heads for seed set. With the exception of 10 seeds produced by one individual, no seeds were produced, indicating that the species does not self, at least in the absence of insect vectors. 
Table 4 Mean observed fixation index $\left(F_{\text {IS }}\right)$ and the equilibrium fixation index $\left(F_{\mathrm{e}}\right)$ for populations of Liatris helleri

\begin{tabular}{lrc}
\hline Population & $F_{\text {IS }}(\mathrm{SE})$ & $F_{\mathrm{e}}$ \\
\hline BH & $-0.266(0.104)$ & 0.064 \\
CR & $0.051(0.089)$ & 0.015 \\
GF & $0.095(0.088)$ & 0.026 \\
RR & $-0.262(0.099)$ & 0.026 \\
SH & $0.225(0.095)$ & 0.000 \\
TR & $-0.213(0.074)$ & 0.000 \\
YO & $-0.300(0.002)$ & 0.015 \\
Mean & $-0.096(0.081)$ & 0.021 \\
\hline
\end{tabular}

\section{Discussion}

Multilocus outcrossing rates for populations of $L$. helleri did not differ significantly from one, suggesting that the species is self-incompatible. The results of greenhouse tests supported this conclusion. Only one of 30 plants with a total of 770 bagged floral heads set a few seeds. The seeds produced by this individual may have resulted from a poor seal on the pollen exclusion bag or a leaky self-incompatibility system. Three other species of Liatris are reported to be obligate outcrossers (Cruise, 1964), as indicated by low levels of seed set in bagged inflorescences.

Significant differences were found between pollen and ovule allele frequencies at certain loci in six of the seven populations surveyed. Nonrandom mating, or gene flow into the populations could contribute to these differences. Pollinators can be preferentially attracted to plants with large floral displays, with the result that such plants may have higher male fertilities (Broyles \& Wyatt, 1990). Thus, although ovule allele frequencies are based on all reproductive individuals collected, pollen allele frequencies represent a sample of the successful pollen and include any biases that may occur in fertility. For $L$. helleri, the number of flowering stalks per plant and inflorescence size vary widely in natural populations and these factors coupled with pollinator foraging behaviour may have contributed to differences between pollen and ovule allele frequencies.

It is also possible that the maternal individuals sampled were not a representative sample of reproductive individuals in the population. A larger number of $L$. helleri plants flowered than set seed. The difference in the numbers of individuals setting seed and flowering resulted from in large part to broken flowering stalks.

Low levels of biparental inbreeding (mating between related individuals) were evident from the significant $t_{\mathrm{m}}-t_{\mathrm{s}}$ values recorded in three of the populations examined. Localized seed dispersal, coupled with local pollen transfer, can lead to the development of population subdivision and biparental inbreeding. Schaal \& Levin (1978) found evidence for population subdivision in a related species, Liatris cylindracea, and attributed it to consanguineous matings. Bees mediate most pollen dispersal in $L$. cylindracea, and travel predominantly between near-neighbours (Levin \& Kerster, 1969; Schaal, 1975). These neighbours are likely to be related, because mean seed dispersal distance for $L$. cylindracea was estimated as $1.61 \mathrm{~m}$ in open surroundings, with a modal distance of $0.75 \mathrm{~m}$ (Schaal $\&$ Levin, 1978). For $L$. helleri, the majority of pollinator movements is also likely to be between closely spaced individuals. However, parameters of $L$. helleri seed dispersal are more difficult to assess. Seeds of $L$. helleri are wind-dispersed, and high winds are common in the mountainous habitat of $L$. helleri, particularly during the autumn when seeds are ripening. The distance that $L$. helleri seeds typically travel, however, before being intercepted by intervening vegetation is unknown.

We found no evidence that biparental inbreeding was associated with the number of flowering plants in a population. Significant levels of inbreeding were not observed in the smallest populations (YO, $\mathrm{SH}$ and $\mathrm{BR}$ ). Because pollinator behaviour is likely to be similar across populations, this suggests that stochastic seed dispersal and establishment may lead to less population structure in some populations. Suitable open habitat is limited in many populations, adding elements of chance to establishment and recruitment.

Overall, equilibrium inbreeding coefficients were low, as expected for an outcrossing species. If the mating system is the sole determinant of genotypic proportions, the equilibrium inbreeding coefficient and the inbreeding coefficient of the adult plants should be similar. For three of the seven populations we found no significant differences. However, in populations RR, TR and YO an excess of heterozygotes was observed in the adult generation, while a deficit of heterozygotes was observed in population $\mathrm{SH}$.

\section{Conservation implications}

It is likely that $L$. helleri has a multiallelic sporophytic incompatibility system, which is typical of the Asteraceae (Richards, 1986). In this self-incompatibility system, populations consist of many mating 
types that differ in ' $S$ ' alleles at the self-incompatibility locus. The ability of the pollen grain to effect fertilization is determined by the similarity between the genotype of the pollen donor and the plant receiving pollen, rather than between the genotype of the pollen grain and the target plant. Frequencydependent selection favours rare $S$ alleles as individuals carrying such alleles are initially compatible with a large number of plants. Theoretically, most populations should contain several alleles in roughly even frequencies. Loss of $S$ alleles during a population bottleneck or during a founding event should decrease the number of compatible mating types, and might lead to decreased reproduction (this can also result from stochastic events in small populations). In the extreme case, all plants could have the same mating type, in which case the population would be effectively sterile. This scenario was documented for a remnant inland population of the lakeside daisy (Hymenoxys acaulis var. glabra), a Great Lake endemic (DeMauro, 1993). A low number of compatible mating types in $L$. helleri populations might explain the large proportion of achenes that were observed to have aborted at the time of collection (M.J.W.G., pers. obs.). Incompatible pollen (either self or outcross) may swamp the stigma or plug the style before outcrossed pollen from a compatible mating type arrives. The small number of reproductive individuals in some Liatris populations suggests that this may not be an unlikely event. However, cross-incompatibility can occur among plants even within large populations, suggesting that compatible mating types may be locally rare (DeMauro, 1993).

Because $L$. helleri is self-incompatible, individuals isolated from the main body of a population may be pollen-limited. However, because $L$. helleri racemes bloom sequentially from top to bottom over a fairly extended period, and because different flowering stalks on the same plant can have different phenologies, opportunities for obtaining outcross pollen are enhanced.

It is evident from the results of the present study that future management and conservation plans for $L$. helleri must take into account its mating system. Restoration efforts are likely to falter or fail if insufficient numbers of cross-compatible mating types are not maintained in populations. Likewise, ex situ conservation and propagation of the species will require a variety of cross-compatible genotypes.

\section{Acknowledgements}

We thank Robert Godt for help in obtaining field samples. Kermit Ritland kindly provided a copy of the mating-system program. Undergraduates Paula Forrester, Jenna Navarre, Kelli Patrick and Ron Jones assisted in laboratory portions of this work. We thank Hugh Morton and Steve Miller for permission to collect seeds from population GF. Two anonymous reviewers provided helpful comments. This research was funded by the U. S. Fish and Wildlife Service, through the state of North Carolina (Contract \# 14-16-004-89-967). We especially thank Nora Murdock for support of this research.

\section{References}

BARRETT, S. C. H. AND KOHN, J. R. 1991. Genetic and evolutionary consequences of small population size in plants: implications for conservation. In: Falk, D. A. and Holsinger, K. E. (eds) Genetics and Conservation of Rare Plants, pp. 3-30. Oxford University Press, New York.

BROWN, A. H. D. 1989. Genetic characterization of plant mating systems. In: Brown, A. H. D., Clegg, M. T., Kahler, A. L. and Weir, B. S. (eds) Plant Population Genetics, Breeding, and Genetic Resources, pp. 145-162. Sinauer Associates, Sunderland, MA.

BROWN, A. H. D. AND ALLARD, R. W. 1970. Estimation of the mating system in open-pollinated maize populations using isozyme polymorphisms. Genetics, 66, 133-145.

BROYLES, S. B. AND WYATT, R. 1990 . Paternity analysis in a natural population of Asclepias exaltata: multiple paternity, functional gender and the "pollen-donation hypothesis". Evolution, 44, 1454-1468.

CHELIAK, W. M. AND PITEL, J. A. 1984. Techniques for Starch Gel Electrophoresis of Enzymes from Forest Tree Species. Petawawa National Forestry Institute, Information Report P1-X-42. Canadian Forestry Service, Agriculture, Canada.

ClEGG, M. T. 1980. Measuring plant mating systems. Bioscience, 30, 814-818.

CRUISE, J. E. 1964. Biosystematic studies of three species in the genus Liatris. Can. J. Bot., 42, 1445-1455.

DEMAURO, M. M. 1993. Relationship of breeding system to rarity in the Lakeside Daisy (Hymenoxys acaulis var. glabra). Conserv. Biol., 7, 542-550.

FYFE, J. L. AND BAILEY, N. T. J. 1951. Plant breeding studies in leguminous forage crops. 1. Natural cross-breeding in winter beans. J. Agric. Sci. Camb., 41, 371-378.

KARRON, J. D. 1991. Patterns of genetic variation and breeding systems in rare plant species. In: Falk, D. A. and Holsinger, K. E. (eds) Genetics and Conservation of Rare Plants, pp. 87-98. Oxford University Press, New York.

LES, D. H., REINARTZ, A. AND ESSELMAN, E. J. 1991. Genetic consequences of rarity in Aster furcatus (Asteraceae), a threatened, self-incompatible plant. Evolution, 45, 1641-1650. 
LEVIN, D. A. AND KERSTER, H. w. 1969. Density-dependent gene dispersal in Liatris. Am. Nat., 103, 61-74.

MASSEY, J. R., OTTE, D. K. S., ATKINSON, T. A. AND WHETSTONE, R. D. 1983. An Atlas and Illustrated Guide to the Threatened and Endangered Vascular Plants of the Mountains of North Carolina and Virginia. Southeastern Forest Experiment Station, Asheville, NC. pp. 94-97.

MITTON, J. B., LINHART, Y. B., STURGEON, K. B. AND HAMRICK, J. L. 1979. Allozyme polymorphisms detected in mature needle tissue of ponderosa pine. J. Hered., 70, 86-89.

RADFORD, A. E., AHLES, H. E. AND BELL, C. R. 1968. Manual of the Vascular Flora of the Carolinas. University of North Carolina Press, Chapel Hill.

RICHARDS, A. J. 1986. Plant Breeding Systems. George Allen \& Unwin, London.

RITLAND, K. AND JAIN, s. K. 1981. A model for the estimation of outcrossing rate and gene frequencies using $n$ independent loci. Heredity, 47, 35-52.

SCHAAL, B. A. 1975. Population structure and local differentiation in Liatris cylindracea. Am. Nat., 109, 511-528.

SCHAAL, B. A. AND LEVIN, D. A. 1978. Morphological differ- entiation and neighborhood size in Liatris cylindracea. Am. J. Bot., 65, 923-928.

SHAW, D. V., KaHLER, A. L. AND ALlard, R. W. 1981. A multilocus estimator of mating system parameters in plant populations. Proc. Natl. Acad. Sci. U.S.A., 78, 1298-1302.

SOLTIS, D. E., HAUFLER, C. H., DARROW, D. C. AND GASTONY, G. J. 1983. Starch gel electrophoresis of ferns: a compilation of grinding buffers, gel and electrode buffers, and staining schedules. Am. Fern J., 73, 9-27.

U.S. FISH AND WILDLIFE SERVICE. 1989. Heller's Blazing Star Recovery Plan. U.S. Fish and Wildlife Service, Atlanta, GA.

WHISLER, S. L. AND A. A. SNOw. 1992. Potential for the loss of self-incompatibility in pollen-limited populations of mayapple (Podophyllum peltatum). Am. J. Bot., 79, $1273-1278$.

WIDÉN, B. 1993. Demographic and genetic effects on reproduction as related to population size in a rare, perennial herb, Senecio integrifolius (Asteraceae). Biol. J. Linn. Soc., 50, 179-195. 